\title{
Mutation of a nicotinic acetylcholine receptor $\beta$ subunit is associated with resistance to neonicotinoid insecticides in the aphid Myzus persicae
}

\author{
Chris Bass $^{1 *}$, Alin M Puinean ${ }^{1+}$, Melanie Andrews ${ }^{2}$, Penny Cutler ${ }^{3}$, Miriam Daniels $^{3}$, Jan Elias ${ }^{2}$, Verity Laura Paul ${ }^{2}$, \\ Andrew J Crossthwaite ${ }^{3}$, lan Denholm¹, Linda M Field ${ }^{1}$, Stephen P Foster ${ }^{1}$, Rob Lind ${ }^{3}$, Martin S Williamson ${ }^{1}$ and \\ Russell Slater $^{2}$
}

\begin{abstract}
Background: Myzus persicae is a globally important aphid pest with a history of developing resistance to insecticides. Unusually, neonicotinoids have remained highly effective as control agents despite nearly two decades of steadily increasing use. In this study, a clone of M. persicae collected from southern France was found, for the first time, to exhibit sufficiently strong resistance to result in loss of the field effectiveness of neonicotinoids.

Results: Bioassays, metabolism and gene expression studies implied the presence of two resistance mechanisms in the resistant clone, one based on enhanced detoxification by cytochrome P450 monooxygenases, and another unaffected by a synergist that inhibits detoxifying enzymes. Binding of radiolabeled imidacloprid (a neonicotinoid) to whole body membrane preparations showed that the high affinity [3H]-imidacloprid binding site present in susceptible M. persicae is lost in the resistant clone and the remaining lower affinity site is altered compared to susceptible clones. This confers a significant overall reduction in binding affinity to the neonicotinoid target: the nicotinic acetylcholine receptor (nAChR). Comparison of the nucleotide sequence of six nAChR subunit (Mpa 1-5 and $\mathrm{Mp} \beta 1$ ) genes from resistant and susceptible aphid clones revealed a single point mutation in the loop $D$ region of the nAChR $\beta 1$ subunit of the resistant clone, causing an arginine to threonine substitution (R81T).

Conclusion: Previous studies have shown that the amino acid at this position within loop $D$ is a key determinant of neonicotinoid binding to nAChRs and this amino acid change confers a vertebrate-like character to the insect $n A C h R$ receptor and results in reduced sensitivity to neonicotinoids. The discovery of the mutation at this position and its association with the reduced affinity of the nAChR for imidacloprid is the first example of field-evolved target-site resistance to neonicotinoid insecticides and also provides further validation of exisiting models of neonicotinoid binding and selectivity for insect nAChRs.
\end{abstract}

\section{Background}

The peach-potato aphid, Myzus persicae is a globally important pest of a broad range of arable and horticultural crops principally due to its ability to transmit more than 100 plant viruses [1]. Its control relies almost exclusively on the application of insecticides and, as a

\footnotetext{
* Correspondence: chris.bass@rothamsted.ac.uk

† Contributed equally

'Centre for Sustainable Pest and Disease Management, Rothamsted Research, Harpenden, AL5 2JQ, UK

Full list of author information is available at the end of the article
}

result, this species has developed multiple resistance to many chemical classes including organophosphates, carbamates and pyrethroids [2]. The molecular mechanisms of resistance to insecticides in $M$. persicae include overproduction of detoxifying carboxylesterases (E4 or FE4) which confers resistance primarily to organophosphates, and two forms of target-site resistance involving mutation of the acetylcholinesterase protein, (modified acetylcholinesterase, MACE) giving insensitivity to dimethyl carbamates, and of the voltage-gated sodium channel

\section{Ciomed Central}


(knockdown resistance, $\mathrm{kdr}$ ) giving resistance to pyrethroids [2]. Neonicotinoids such as imidacloprid, thiamethoxam, clothianidin and acetamiprid are unaffected by these mechanisms and are currently the main means of control. Despite two decades of steadily increasing use neonicotinoids have proved remarkably resilient to the development of resistance and have remained highly effective against $M$. persicae. Samples of $M$. persicae with reduced susceptibility to neonicotinoid compounds (10-40 fold resistance) have been found in Europe, the USA and Japan [3-5]. However, at present the levels of resistance described have limited practical significance as they are insufficient to impair the field effectiveness of these insecticides $[3,5]$.

Recently, biochemical and genomic approaches were used to investigate neonicotinoid resistance in a $M$. persicae clone from Greece showing $\sim 40$ fold resistance to neonicotinoids [6,7]. Resistance was associated with multiple duplications of a single P450 gene (CYP6CY3), with resistant aphids carrying 18 copies of the gene compared to the two copies found in susceptible aphids. However, ligand-binding and sequencing studies provided no evidence that structural modification of the nicotinic acetylcholine receptor (nAChR; the neonicotinoid target site) contributed to resistance in this clone. Although aphids have continued to be effectively controlled by neonicotinoids, resistance is a significant problem in other insect species including the Colorado potato beetle (Leptinotarsa decemlineata), the brown planthopper (Nilaparvata lugens) and the tobacco whitefly (Bemisia tabaci) [5]. As found for $M$. persicae, overexpression of one or more P450s appears to be the primary mechanism of neonicotinoid resistance in insect pests $[5,8]$. The only alternative mechanism described to date was modification of the target-site in a laboratory-selected strain of $N$. lugens, when resistance was associated with a point mutation in two nAChR alpha subunits (Nlo1 and Nlo3) [9]. However, resistance in field populations of $N$. lugens appears to occur exclusively via P450-mediated detoxification $[10,11]$ and, to date, no case of target-site insensitivity to neonicotinoids has been described in individuals of any insect pest collected directly from the field.

The selectivity of neonicotinoids for insects is thought to be due, at least in part, to their high affinity for insect nAChRs [12]. Nicotinic receptors are ligand-gated ion channels made up of five subunits arranged in combinations from a family of different subunit subtypes [13]. Insect genomes sequenced to date have contained around ten genes encoding alternative $\mathrm{nAChR}$ subunit subtypes and six genes have been characterised in $M$. persicae [14].

We report here, for the first time, a clone of $M$. persicae with extremely potent resistance to neonicotinoids that compromises the field effectiveness of members of this insecticide class. We provide evidence that both
P450-mediated detoxification of neonicotinoids and target-site insensitivity confer the resistance phenotype. This is the first example of field-evolved target-site resistance to neonicotinoid insecticides.

\section{Results}

\section{Topical bioassays}

A clone of $M$. persicae (FRC) originating from peach orchards in Southern France exhibited potent resistance to imidacloprid and thiamethoxam when compared to a susceptible clone (4106A) in insecticide bioassays using two different methods of topical application (Table 1). Indeed, using a micro-application method (applying insecticide directly to the dorsal surface of individual aphids), resistance was immeasurable due to insufficient mortality at the highest concentration that could be applied. A comparison of the resistance profile of FRC with 5191A (previously the most neonicotinoid-resistant $M$. persicae clone described) using the same bioassay method (Table 1) highlights the significantly enhanced level of resistance exhibited by FRC. Spray application bioassays, which combine direct contact with insecticide and subsequent exposure to residues on leaves, gave measurable resistance factors of 1679 - and 225-fold to imidacloprid and thiamethoxam respectively. In the micro-application assays there was evidence that pretreatment with the metabolic enzyme inhibitor piperonyl butoxide (PBO) synergised the effect of thiamethoxam (Table 1) although high levels of resistance remained (RF of 800). The effect of pre-treatment with PBO was more evident in spray application bioassays, with resistance factors reduced to 234-fold for imidacloprid and 26-fold for thiamethoxam (Table 1).

\section{Imidacloprid metabolism}

The metabolism of imidacloprid (1-(6-chloro-3-pyridylmethyl)-N-nitroimidazolidin-2-ylideneamine) has been well characterised in mammals, plants, soil and some insect species [15]. Whilst a range of primary metabolites have been identified, the major metabolic pathway identified in many species is hydroxylation and desaturation of the imidazolidine ring to form the hydroxy and olefin metabolites [15]. Initial LC-MS/MS analysis investigating ten selected metabolites (Additional file 1) revealed that the 4/5-hydroxy metabolite was the only metabolite detected in aphids treated with a topical application of imidacloprid. Therefore, subsequent analysis focused on parent imidacloprid and the 4/5-hydroxy metabolite to determine whether there were differences in imidacloprid metabolism between FRC and 4106A.

LC-MS/MS analysis did reveal significant differences in imidacloprid metabolism between FRC and 4106A. For $4106 \mathrm{~A}$, recovery of imidacloprid increased in a timedependent manner over the course of the experiment, 
Table 1 Response of Myzus persicae clones 4106A (susceptible), 5191A (moderately resistant) and FRC (highly resistant) to imidacloprid and thiamethoxam using two bioassay methods, with and without pretreatment with piperonyl butoxide (PBO)

\begin{tabular}{|c|c|c|c|c|c|c|c|}
\hline & & Micro-application & & & Spray applica & & \\
\hline Treatment & Clone & $\mathrm{LC}_{50}{ }^{1}\left(\mathrm{mg} \mathrm{l}^{-1}\right)$ & $95 \% \mathrm{CL}$ & $\mathrm{RF}^{2}$ & $\mathrm{LC}_{50}\left(\mathrm{mg} \mathrm{l}^{-1}\right)$ & $95 \% \mathrm{CL}$ & $\mathrm{RF}^{2}$ \\
\hline \multirow[t]{3}{*}{ Imidacloprid } & $4106 \mathrm{~A}$ & 0.99 & $0.9-1.4$ & & 0.14 & $0.11-0.17$ & - \\
\hline & 5191A & 31.1 & $7-69.7$ & 31.4 & - & - & - \\
\hline & FRC & $28 \%$ at $1000 \mathrm{mg} \mathrm{l}^{-1}$ & $n / c$ & $n / c$ & 235.02 & $142.33-476.29$ & 1679 \\
\hline \multirow[t]{3}{*}{ Imidacloprid+PBO } & $4106 \mathrm{~A}$ & 0.1 & $0.07-0.15$ & & 0.03 & $0.01-0.10$ & - \\
\hline & $5191 \mathrm{~A}$ & 1.55 & $0.56-2.55$ & 14.9 & - & - & - \\
\hline & FRC & $30 \%$ at $1000 \mathrm{mg} \mathrm{l}^{-1}$ & $\mathrm{n} / \mathrm{c}$ & $\mathrm{n} / \mathrm{c}$ & 7.03 & $1.77-37.91$ & 234 \\
\hline \multirow[t]{3}{*}{ Thiamethoxam } & $4106 \mathrm{~A}$ & 0.64 & $0.54-0.79$ & & 0.48 & $0.42-0.55$ & - \\
\hline & $5191 \mathrm{~A}$ & 19.7 & $14.87-25.74$ & 30.8 & - & - & - \\
\hline & FRC & $10 \%$ at $1000 \mathrm{mg} \mathrm{l}^{-1}$ & $\mathrm{n} / \mathrm{c}$ & $\mathrm{n} / \mathrm{c}$ & 107.84 & $69.52-185.36$ & 225 \\
\hline \multirow[t]{3}{*}{ Thiamethoxam+PBO } & $4106 \mathrm{~A}$ & 0.27 & $0.18-0.32$ & & 0.19 & $0.09-0.41$ & - \\
\hline & $5191 \mathrm{~A}$ & 1.06 & $0.77-1.45$ & 3.93 & - & - & - \\
\hline & FRC & 216 & $110.25-483.48$ & 800 & 4.86 & $2.03-14.91$ & 26 \\
\hline
\end{tabular}

$5191 \mathrm{~A}$ was only tested by micro-application of insecticide.

${ }^{1}$ Calculated concentration to kill $50 \%$ of individuals. If unobtainable, $\%$ mortality at the highest concentration applied.

${ }^{2}$ Resistance factor ( $\mathrm{LC}_{50}$ resistant/LC 50 susceptible). $\mathrm{n} / \mathrm{c}=$ not calculable.

reaching a maximum of $0.43( \pm 0.06) \mathrm{ng} \mathrm{mg}^{-1}$ of aphids after $24 \mathrm{~h}$ (Figure $1 \mathrm{~A})$, suggesting that the rate of imidacloprid uptake across the cuticle was greater than the rate of imidacloprid metabolism and excretion. In contrast, for FRC the recovery of imidacloprid decreased in a time-dependent manner, reaching a minimum of 0.19 $( \pm 0.05) \mathrm{ng} \mathrm{mg}^{-1}$ of aphids after $24 \mathrm{~h}$ (Figure 1A). In terms of metabolite production, in clone 4106A recovery of the 4/5-hydroxy metabolite was variable, often being below the limit of detection and/or limit of quantification. However, in the FRC clone, this metabolite was more consistently detected and was produced in a timedependant manner, reaching a maximum $(21.24$ ( \pm 5.80$)$ relative peak area/mg of aphid) after $24 \mathrm{~h}$ (see Figure $1 \mathrm{~B}$ ). Although the 4/5-hydroxy metabolite has been shown to possess some insecticidal activity, its specific activity at the $\mathrm{nAChR}$ is weaker than imidacloprid [16].

\section{Microarray Analysis}

Microarray analysis identified 571 genes significantly differentially transcribed between FRC and 4106A. The full list of these genes along with $\log _{2}$, calculated foldchange values and a description based on the closest BLAST hit is given in Additional file 2. 349 genes (213 of unknown function) had elevated expression in FRC and 222 (143 of unknown function) were under-transcribed in this clone relative to 4106A. Of the 136 overexpressed genes with a known function, 26 were potential candidates for being involved in insecticide resistance and are listed in Table 2. These included genes encoding cytochrome P450s, carboxylesterase E4/FE4 and a glutathione-S-transferase.

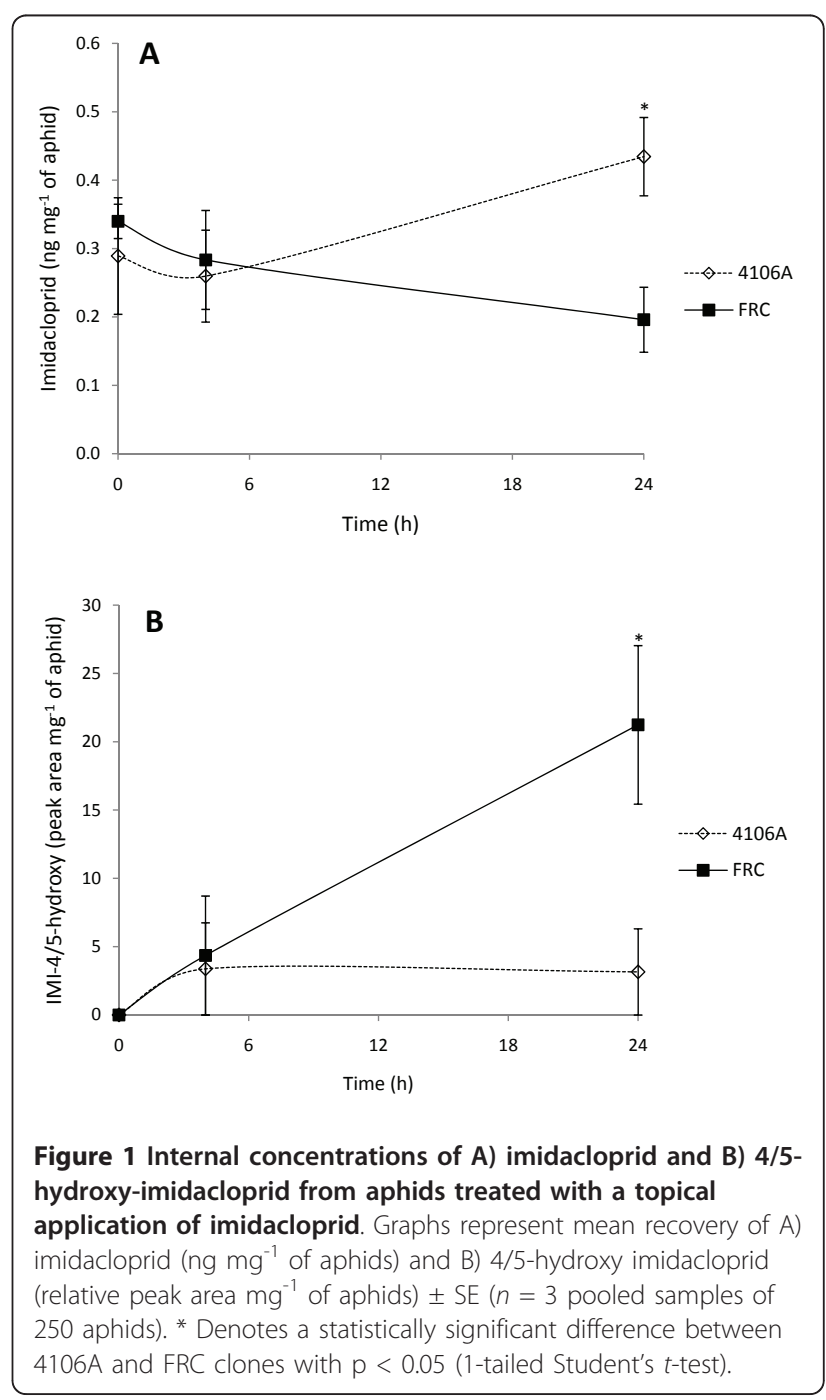


Table 2 Selected genes identified by microarray as significantly differentially transcribed between the insecticide resistant $M$. persicae clone (FRC) and the susceptible clone (4106A)

\begin{tabular}{|c|c|c|c|}
\hline Description & $\begin{array}{l}\text { Mean } \\
\log 2\end{array}$ & $\begin{array}{l}\text { Fold } \\
\text { change }\end{array}$ & $\begin{array}{l}\text { Parent } \\
\text { sequence ID }\end{array}$ \\
\hline ref|X74555.1| M.persicae mRNA for esterase FE4 & 8.18 & 290.98 & contig3118 \\
\hline ref|X74555.1| M.persicae mRNA for esterase FE4 & 6.99 & 127.91 & 454Myzus_30192 \\
\hline ref|X74554| M.persicae mRNA for esterase E4 & 5.95 & 62.07 & contig720 \\
\hline ref|X74555.1| M.persicae mRNA for esterase FE4 & 5.78 & 55.25 & contig9215 \\
\hline ref|X74554| M.persicae mRNA for esterase E4 & 5.44 & 43.60 & contig720 \\
\hline ref|X74554| M.persicae mRNA for esterase E4 & 5.40 & 42.39 & contig4586 \\
\hline ref|HM009309|Myzus persicae cytochrome P450 (CYP6CY3) mRNA, complete cds & 3.76 & 13.60 & contig749 \\
\hline ref|HM009309|Myzus persicae cytochrome P450 (CYP6CY3) mRNA, complete cds & 3.72 & 13.26 & contig749 \\
\hline ref|HM009309|Myzus persicae cytochrome P450 (CYP6CY3) mRNA, complete cds & 3.46 & 11.01 & contig497 \\
\hline ref|HM009309|Myzus persicae cytochrome P450 (CYP6CY3) mRNA, complete cds & 3.37 & 10.40 & contig497 \\
\hline ref|HM009309|Myzus persicae cytochrome P450 (CYP6CY3) mRNA, complete cds & 3.34 & 10.18 & 454Myzus_77428 \\
\hline ref|HM009309|Myzus persicae cytochrome P450 (CYP6CY3) mRNA, complete cds & 3.19 & 9.15 & contig5173 \\
\hline ref|XM_001952692.1| PREDICTED: Acyrthosiphon pisum similar to cytochrome P450 (LOC100163313) & 2.12 & 4.36 & 454Myzus_27444 \\
\hline $\begin{array}{l}\text { ref|XM_001946504.1| PREDICTED: Acyrthosiphon pisum similar to glutathione S-transferase-like protein, } \\
\text { transcript variant } 1 \text { (LOC100168850) }\end{array}$ & 1.55 & 2.94 & contig3513 \\
\hline $\begin{array}{l}\text { ref|XM_001947885.1| PREDICTED: Acyrthosiphon pisum similar to cytochrome P450 CYP6AX1 protein } \\
\text { (LOC100160895) }\end{array}$ & 1.49 & 2.83 & 454Myzus_26873 \\
\hline ref|XP_001944530.1| PREDICTED: similar to cytochrome P450 4A7 [Acyrthosiphon pisum] & 1.47 & 2.78 & contig2519 \\
\hline ref|XM_001944991.1| PREDICTED: Acyrthosiphon pisum similar to cytochrome P450 4A7 (LOC100162710) & 1.43 & 2.70 & 454Myzus_27229 \\
\hline ref|XM_001944991.1| PREDICTED: Acyrthosiphon pisum similar to cytochrome P450 4A7 & 1.41 & 2.67 & contig1504 \\
\hline ref|XM_001944495.1| PREDICTED: Acyrthosiphon pisum similar to cytochrome P450 4A7 (LOC100158738) & 1.40 & 2.65 & 454Myzus_82930 \\
\hline ref|XM_001944991.1| PREDICTED: Acyrthosiphon pisum similar to cytochrome P450 4A7 & 1.30 & 2.55 & contig1504 \\
\hline $\begin{array}{l}\text { ref|XM_001947885.1| PREDICTED: Acyrthosiphon pisum similar to cytochrome P450 CYP6AX1 protein } \\
\text { (LOC100160895) }\end{array}$ & 1.34 & 2.55 & contig643 \\
\hline $\begin{array}{l}\text { ref|XM_001947885.1| PREDICTED: Acyrthosiphon pisum similar to cytochrome P450 CYP6AX1 protein } \\
\text { (LOC100160895) }\end{array}$ & 1.33 & 2.52 & DW362118.1 \\
\hline $\begin{array}{l}\text { ref|XM_001947885.1| PREDICTED: Acyrthosiphon pisum similar to cytochrome P450 CYP6AX1 protein } \\
\text { (LOC100160895) }\end{array}$ & 1.26 & 2.40 & contig643 \\
\hline ref|XM_001948546.1| PREDICTED: Acyrthosiphon pisum similar to cytochrome P450 CYP6AX1 protein & 1.23 & 2.35 & 454Myzus_74544 \\
\hline ref|XM_001948386.1| PREDICTED: Acyrthosiphon pisum similar to cytochrome P450 CYP6AX1 protein & 1.18 & 2.28 & contig4886 \\
\hline ref|NM_001163211.1| Acyrthosiphon pisum cytochrome P450 protein & 1.07 & 2.10 & contig1501 \\
\hline
\end{tabular}

Five EST sequences encoding carboxylesterase FE4 and the closely related variant E4 were identified as overexpressed in the resistant clone. However the level of expression was variable (ranging from 42-291-fold) probably because as reported previously only one of the five ESTs (contig 3118) is a perfect match with E4/FE4 [7]. It is likely that the fold-change indicated by hybridisation to the probe designed on contig 3118 is the most accurate and this showed a $\sim 290$-fold over-expression.

Five EST sequences (Table 2) corresponding to the $M$. persicae cytochrome $\mathrm{P} 450$ gene CYP6CY3 showed elevated expression in the FRC clone (9-14-fold). Overexpression of this gene was reported previously to be associated with moderate levels (25-40-fold) of resistance to neonicotinoids in the $M$. persicae clone 5191A (see introduction). Eleven additional EST sequences encoding P450s were also overexpressed in the FRC clone but the changes observed were relatively low (2-4-fold). Analyses of these sequences indicated that the 11 ESTs probably correspond to seven cytochrome P450 genes. Two are most similar in sequence to the Acyrthosiphon pisum P450 genes CYP380C3 (represented by ESTs 2519 and 82930), and CYP380C5v1 (represented by ESTs 27229 and 1504) that belong to the CYP4 clade. The remaining five genes are most similar to the $A$. pisum $\mathrm{P} 450$ genes, CYP6CY2 (represented by EST 27444), CYP6CY4 (represented by EST 74544), CYP6CY7 (represented by ESTs 26873, 643 and DW362118), CYP6CY8 (represented by EST 1501) and CYP6CY17 (represented by EST 4886) belonging to the CYP3 clade. Finally, a single GST gene most similar in sequence to other insect GSTs of the sigma class showed a moderate ( $\sim 3$-fold) increase in expression in FRC compared to 4106A.

Among the 79 genes of known function that were under-transcribed in FRC relative to 4106A, a limited number of detoxification genes were identified (see Additional file 2). These included four sequences 
encoding GSTs with a negative fold change of -2 to -10 , two sequences encoding CYP6-type cytochrome P450s and one sequence encoding a CYP4-type P450 with a fold change of -2 to -3.5 .

Real-time quantitative PCR was used to validate microarray results by examining the expression profile of $C Y P 6 C Y 3$ and the seven additional over-expressed P450 genes. Expression was compared simultaneously between FRC, 4106A and 5191A (Additional file 3). In all cases the increased transcription of the genes was confirmed (apart from the P450 gene encoded by EST 27444 which could not be amplified by PCR despite repeated attempts using several alternative primer pairs). As shown in Additional file 3 the CYP6CY3 gene was over-transcribed in FRC 28-fold compared to 4106A but this was not significantly different to the level of expression in 5191A. Overexpression of this gene in 5191A was previously shown to be due, in part, to a 9-fold amplification of the structural gene [7]. Quantitative PCR was therefore used to determine CYP6CY3 gene copy number in the FRC clone using genomic DNA as template and normalising data to the para gene present in two copies in diploid insect genomes. FRC showed a fold change in copy number of $8.3+/-0.52$ comparable to that in $5191 \mathrm{~A}$. Of the remaining $\mathrm{P} 450$ genes, five (two CYP4 and three CYP6-type) were found to be overexpressed in FRC compared to both 4106A and 5191A although the fold-changes observed were low (23 -fold). The exception was the $\mathrm{P} 450$ gene represented by EST 74544 which showed a higher (7-fold) level of overexpression. However, this gene was also overexpressed at a similar level in 5191A suggesting it is not involved in the enhanced resistance phenotype displayed by FRC.

\section{Radioligand binding assays}

Radioligand binding assays of [3H]-imidacloprid to aphid membrane preparations revealed substantial differences in the nature of imidacloprid binding between FRC and 4106A. As described previously, [3H]-imidacloprid recognised two sites in the susceptible $4106 \mathrm{~A}$ clone, one of very high (sub $n M)$ affinity and a second lower $(\sim n M)$ affinity site [17] (Figure 2A and 2B, Table 3). In the FRC clone the dual nature of $[3 \mathrm{H}]$-imidacloprid binding was absent with only a single lower affinity binding site present, as demonstrated by a Hill value close to unity (Figure 2, Table 3), resulting in an overall reduction in binding affinity. In addition, this single binding site was present at far greater concentrations than that observed for the $[3 \mathrm{H}]$-imidacloprid binding sites in 4106A indicated by the substantially increased $B_{\max }$ value in the FRC clone. The $\mathrm{K}_{\mathrm{d}}$ values recorded in this study for wildtype $M$. persicae differ somewhat from those recorded previously $(0.14 \pm 0.01$ and $12.58 \pm 1.83 \mathrm{nM})$ [17]

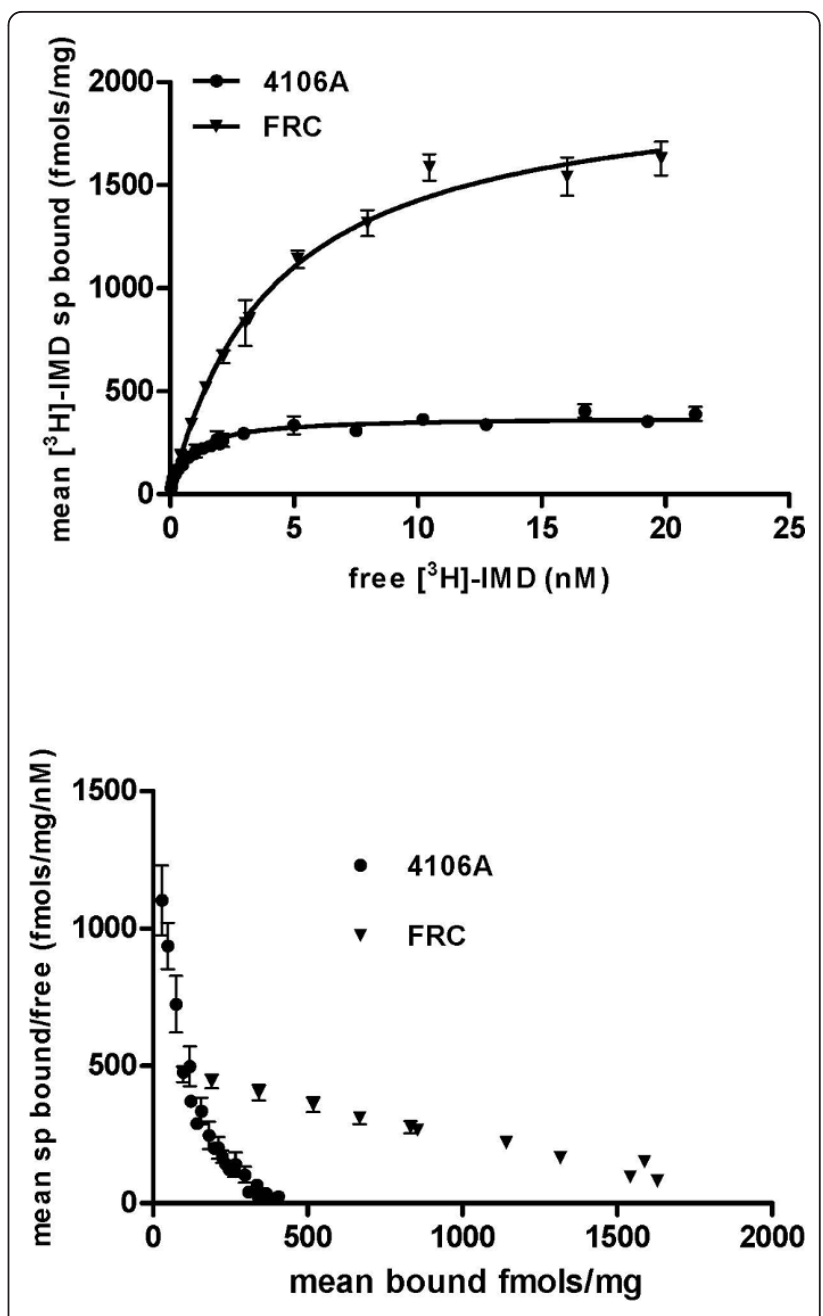

Figure 2 (A) Comparative saturation isotherms of $3 \mathrm{H}-\mathrm{IMD}$ binding in crude membranes from 4106A and FRC Myzus persicae clones, using MLA as the non-specific ligand ( $n=3$ +/-SD). (B) Scatchard plot of data derived from (A) demonstrating the presence of multiple binding sites in 4106A but only a single binding site in FRC.

however, there are some significant experimental differences between the two studies. Firstly, in this study larger final incubation volumes $(1 \mathrm{ml})$ were used to avoid ligand depletion at very low concentrations of added [3H]-imidacloprid. Secondly, two different wild-type strains were used, US1L by Lind et al and 4106A in this study.

\section{Sequence analysis of $M$. persicae $\mathrm{nAChR}$ subunit genes}

The N-terminal region of the $M$. persicae nAChR $\alpha 1-\alpha 5$ and $\beta 1$ subunits, encompassing the conserved domains (loops A to F) that comprise the acetylcholine and neonicotinoid binding site were amplified by PCR from FRC, 5191A, and 4106A and examined by nucleotide sequencing. Although a limited number of silent SNPs were detected in the nucleotide sequence of the nAChR 
Table 3 [3H]-imidacloprid saturable binding to membrane preparations of the FRC and 4106A M. persicae clones using methyllycaconitine as the non-specific ligand ( $n=3+/-S D)$

\begin{tabular}{cccccc}
\hline Clone & \multicolumn{2}{c}{ High affinity } & \multicolumn{3}{c}{ Low affinity } \\
& $\mathbf{k d}(\mathbf{n M})$ & $\mathbf{B m a x}(\mathbf{f m o l s} / \mathbf{m g})$ & $\mathbf{k d}(\mathbf{n M})$ & Bmax $(\mathbf{f m o l s} / \mathbf{m g})$ & Hill value $\left(\boldsymbol{n}_{\mathbf{H}}\right)$ \\
\hline FRC & - & - & $4.14( \pm 0.39)$ & $2016( \pm 70.5)$ & $1( \pm 0.005)$ \\
$4106 \mathrm{~A}$ & $0.083( \pm 0.0085)$ & $100( \pm 55)$ & $1.7( \pm 0.65)$ & $298( \pm 48)$ & $0.78( \pm 0.072)$ \\
\hline
\end{tabular}

$\alpha 1-\alpha 5$ subunits, no non-synonymous changes were observed and the deduced amino acid sequence in the region studied was identical between all clones. In contrast, when the sequence of the Mp $\beta 1$ subunit was compared a non-synonymous SNP was observed exclusive to FRC that causes an amino acid replacement of arginine (AGA) to threonine (ACA) at amino acid position 81 within loop $D$, a predicted agonist binding site of nAChR $\beta$ subunits (Table 4). Additional sequencing of RT-PCR products derived from RNA extracted from individuals confirmed that this mutation is homozygous in FRC.

\section{Discussion}

The neonicotinoids are the fastest growing class of insecticides in the global crop protection market with annual worldwide sales of over $\$ 1.5$ billion [18]. They have remained effective against $M$. persicae because they circumvent the resistance mechanisms that have evolved to other insecticide classes, and have so far not been compromised by the evolution of novel mechanisms. In this study we have characterised a field-derived clone (FRC) of $M$. persicae exhibiting sufficiently high levels of neonicotinoid resistance to impair field performance of

\section{Table 4 Alignment of amino acid sequence in loop $D$ of the agonist binding site of vertebrate and insect nicotinic acetylcholine receptors}

\begin{tabular}{|c|c|c|c|c|c|c|c|c|c|c|c|}
\hline \multirow[b]{2}{*}{ Species } & \multicolumn{11}{|c|}{$\begin{array}{l}\text { Amino Acid Number of Myzus persicae } \beta 1 \\
\text { Subunit }\end{array}$} \\
\hline & 77 & 78 & 79 & 80 & 81 & 82 & 83 & 84 & 85 & 86 & 87 \\
\hline Homo sapiens $\beta 2$ & $\mathrm{~N}$ & V & W & $L$ & $\mathrm{~T}$ & Q & $E$ & W & $E$ & D & Y \\
\hline Gallus gallus $\beta 2$ & $\mathrm{~N}$ & V & W & $L$ & $\mathbf{T}$ & Q & $E$ & W & $E$ & D & Y \\
\hline Rattus norvegicus $\beta 2$ & N & V & W & $L$ & $\mathbf{T}$ & Q & $E$ & W & $E$ & D & Y \\
\hline $\begin{array}{l}\text { Drosophila } \\
\text { melanogaster } \beta 1\end{array}$ & C & V & W & $L$ & $\mathbf{R}$ & $L$ & V & W & Y & D & Y \\
\hline Anopheles gambiae $\beta 1$ & $\mathrm{~N}$ & V & W & $L$ & $\mathbf{R}$ & $L$ & V & W & $S$ & D & Y \\
\hline Bemisia tabaci $\beta 1$ & $\mathrm{~N}$ & V & W & $L$ & $\mathbf{R}$ & $L$ & V & W & $\mathrm{N}$ & D & Y \\
\hline Locusta migratoria $\beta 1$ & N & V & W & $L$ & $\mathbf{R}$ & $L$ & V & W & $\mathrm{N}$ & D & Y \\
\hline Heliothis virescens $\beta 1$ & $N$ & V & W & $L$ & $\mathbf{R}$ & $L$ & V & W & M & $\mathrm{D}$ & Y \\
\hline Ctenocephalides felis $\boldsymbol{\beta} 1$ & $\mathrm{~N}$ & V & W & $L$ & $\mathbf{R}$ & $L$ & V & W & S & D & Y \\
\hline $\begin{array}{l}\text { Myzus persicae } 4106 \mathrm{~A} \\
\beta 1\end{array}$ & N & V & W & $L$ & $\mathbf{R}$ & $L$ & V & W & $\mathrm{R}$ & D & Y \\
\hline $\begin{array}{l}\text { Myzus persicae } 5191 \text { A } \\
\beta 1\end{array}$ & N & V & W & $L$ & $\mathbf{R}$ & $L$ & V & W & $\mathrm{R}$ & D & Y \\
\hline Myzus persicae FRC $\beta 1$ & $\mathrm{~N}$ & V & W & L & $\mathrm{T}$ & $L$ & V & W & $\mathrm{R}$ & D & Y \\
\hline
\end{tabular}

these insecticides. The involvement of P450-mediated detoxification in resistance was initially implicated by the use of PBO, an inhibitor of metabolic enzymes including P450s, which was found to alter the phenotype of the resistant clone. Further evidence was provided by LC-MS/MS analysis of imidacloprid metabolism, which demonstrated that the 4/5-hydroxy-imidacloprid metabolite, a product of phase I reactions catalysed by microsomal P450s [15], was produced at higher levels in FRC than the susceptible clone (4106A). Microarray and quantitative real-time PCR analyses showed that a cytochrome P450 gene CYP6CY3 was overexpressed in the FRC clone 28-fold and this was due in part to an eightfold amplification of the structural gene. Amplification of this gene has been reported previously for $M$. persicae where it was associated with moderate (25-40-fold) resistance to neonicotinoids in a clone from Greece (5191A) [7]. However, the levels of expression of this gene in FRC and 5191A were not significantly different and are therefore unlikely to explain the significantly enhanced levels of resistance seen in the FRC clone. A small number of additional P450 genes were found to be overexpressed in FRC compared to both 4106A and 5191A. However, the level of overexpression was relatively low (2-3) fold and while it is possible the proteins encoded by these genes may play some role in resistance it is unlikely their overexpression explains the significantly enhanced level of resistance exhibited by FRC compared to 5191A. The gene encoding carboxylesterase FE4 was also highly overexpressed ( 290 -fold) in FRC but this is an established mechanism of resistance to other insecticides that has been shown to have no effect on neonicotinoids $[7,19]$.

Bioassays also provided strong evidence of an additional major mechanism(s) in resistance with a significant resistance factor remaining in the FRC clone to both thiamethoxam and imidacloprid after synergism by PBO. To investigate the possibility of target-site insensitivity in resistance, the binding of $[3 \mathrm{H}]$-imidacloprid to membrane preparations of FRC and 4106A was compared. Previous binding studies with a range of insect species have demonstrated that while all insect species examined have a binding site for imidacloprid, Hemipteran insects including $M$. persicae have two sites, one of very high affinity and a second of lower affinity $[17,20]$. This may account for the enhanced efficacy of 
imidacloprid against sap-feeding insects such as aphids, leafhoppers and planthoppers [17]. In a previous study no difference in the binding of $[3 \mathrm{H}]$-imidacloprid to membrane preparations from 5191A and 4106A was observed [7]. However, in this study we found the high affinity $[3 \mathrm{H}]$-imidacloprid binding site had been lost in FRC and the remaining lower affinity site was altered, resulting in a substantial overall reduction in binding affinity. Recent study of nAChR subunits in the Hemipteran $N$. lugens has suggested which subunits of the $\mathrm{nAChR}$ contribute to the formation of the imidacloprid binding site [17]. This work has shown that the Nl $\beta 1$ subunit is an absolute requirement for imidacloprid binding and that $\mathrm{nAChRs}$ containing Nl 1 , Nl 2 and $\mathrm{Nl} \beta 1$ constitute the lower affinity site whereas nAChRs containing Nl $\alpha 3, \mathrm{Nl} \alpha 8$ and $\mathrm{Nl} \beta 1$ constitute the higher affinity site [20]. To see if mutation of the orthologous nAChR subunits was associated with resistance in FRC the nucleotide sequence of the $\mathrm{N}$-terminal (agonist binding) region of six $\mathrm{nAChR}$ subunit (Mpa1-5 and Mp $\beta 1$ ) genes from FRC, 4106A and 5191A was compared. No non-synonymous changes were observed between clones in any nAChR $\alpha$ subunit. However, a single point mutation in the loop $\mathrm{D}$ region of the $\mathrm{nAChR}$ $\beta 1$ subunit of the FRC clone was identified that causes an arginine to threonine substitution (R81T). Loop D is one of three regions of the $\beta 1$ subunit that in combination with loops A, B and C of $\alpha$ subunits form the acetylcholine binding site [21]. Several lines of experimental evidence indicate that the amino acid at this position within loop $\mathrm{D}$ is a key determinant of neonicotinoid binding to nAChRs. Insect $\beta 1$ receptors are highly conserved at this amino acid position and all insect species characterised to date have a positively charged arginine at this position (Table 4). In contrast, vertebrate $\beta$ subunits rarely have a positively charged amino acid at this position with the most common residue being a threonine (Table 4). Indeed, the high sensitivity of insect nAChRs to neonicotinoids is thought to be due to interactions between the distinctive electronegative pharmacophore (nitro or cyano group) of these insecticides and conserved residues upstream of loop B, within loop $C$ of $\alpha$ subunits, and certain positively charged residues in loop D (such as R81) of $\beta$ subunits [12,22,23]. Crystallization of molluscan ACh-binding proteins, homologous to the amino-terminal ligand binding domain of nAChR subunits, has confirmed that neonicotinoids bind to nAChRs at the same site as acetylcholine and that amino acids at the corresponding position to $\mathrm{R} 81$ are in close proximal contact with imidacloprid [24]. The most compelling evidence that $\mathrm{R} 81 \mathrm{~T}$ reduces neonicotinoid binding comes from site-directed mutagenesis and homology modelling studies of vertebrate and insect recombinant receptors [22]. Substituting the threonine residue in the chicken $\beta 2$ subunit at position 77 (corresponding to the Mp $\beta 1$ subunit position 81) with arginine or another basic residue greatly enhanced the affinity of recombinant nAChRs (such as Drosophila melanogaster D 2 2/chicken $\beta 2$ hybrids) for imidacloprid. However, this effect was only seen following an additional substitution of a nearby residue in the chicken $\beta 2$ subunit (E79V) to mimic insect $\beta 1$ subunits which, in contrast to vertebrate $\beta$ subunits, have a valine at this position. Models of the recombinant receptors indicated that the nitro group of imidacloprid interacts directly with the introduced basic residue at this position [22]. Interestingly, and importantly, the T77R substitution did not significantly affect the binding affinity of the natural agonist acetylcholine. The mutation described in this study therefore appears to confer a 'vertebrate-like' quality to the $\beta 1$ subunit of resistant aphids resulting in reduced sensitivity of the $\mathrm{nAChR}$ to neonicotinoids through the loss of direct electrostatic interactions of the electronegative pharmacophore with the basic arginine residue at this key position within loop D. The discovery of the mutation at a predicted resistance 'hotspot' [22] and its association with the reduced affinity of the nAChR for imidacloprid also provides further validation of existing models of neonicotinoid binding and selectivity for insect nAChRs.

In a recent study of neonicotinoid resistant housefly, Musca domestica reduced expression of a nAChR alpha subunit (Mdo2) was correlated with the resistance phenotype [25]. Given that radioligand binding assays revealed significant changes to the nature of imidacloprid binding in the FRC strain it would be interesting, in future, to investigate if changes in the expression of different $n A C h R$ subunit genes are also associated with resistance.

The relative role of the two mechanisms (P450-mediated detoxification and target-site insensitivity) in determining the resistance phenotype warrants further study. In particular, the potency and dominance characteristics of targetsite resistance alone, and the practical impact of different combinations of mechanisms on the efficacy of foliar and systemic applications of neonicotinoids remain to be investigated. It is possible that target-site resistance has evolved in a genetic background of enhanced $\mathrm{P} 450$ production and that the mechanisms act synergistically to confer unprecedented levels of resistance to neonicotinoids in $M$. persicae.

\section{Conclusions}

In summary, we describe, for the first time, a clone of $M$. persicae exhibiting control-compromising levels of resistance to neonicotinoid insecticides. We demonstrate that resistance is associated with enhanced imidacloprid metabolism and over-expression of cytochrome P450s but that additional major mechanisms based on reduced affinity of the target-site to the neonicotinoid imidacloprid 
are involved. We provide strong evidence that resistance is conferred, in part, through mutation of a key residue in the loop $\mathrm{D}$ region of a $\mathrm{nAChR} \beta 1$ subunit and this represents the first example of field-evolved target-site resistance to neonicotinoid insecticides.

\section{Methods}

\section{Aphid Clones}

All aphid lines used in this study were clonal lineages derived from a single founding female. 4106A was an insecticide-susceptible clone originating from potatoes in Scotland in 2000. Clone 5191A originated from tobacco in Greece in 2007, and exhibited 20-40 fold resistance to neonicotinoids [6,7]. Clone FRC was derived from a sample collected from peach orchards in Southern France in 2009, following reports of reduced control with neonicotinoids. All clones were reared on Chinese cabbage under standardised conditions [7].

\section{Insecticide Bioassays}

Two bioassay methods were used to establish the extent of neonicotinoid resistance in the FRC clone using insecticide alone and $5 \mathrm{~h}$ after pre-treatment with $\mathrm{PBO}$ to investigate the potential contribution to resistance of detoxifying enzymes that are inhibited by this synergist [6]. The 'micro-application' bioassay involved dosing individual aphids on the dorsal surface with $0.25 \mu \mathrm{l}$ of acetone plus insecticide using a micro-applicator (Burkhard) and measuring mortality $72 \mathrm{~h}$ later as previously described [7]. The 'spray application' bioassay involved spraying insecticide onto aphids and foliage inside a Potter-Precision laboratory spray tower (Burkhard) [26] For this formulated imidacloprid (Confidor $200 \mathrm{~g} / \mathrm{L}$ SL Bayer S.A. Division Agro, France) and thiamethoxam (Actara 25WG Syngenta Crop Protection AG, Basel, Switzerland) was used. For synergism assays piperonyl butoxide was formulated by Syngenta chemists as an $80 \%$ EC and applied in $0.01 \%$ non-ionic surfactant, Extravon (Syngenta Crop Protection AG, Basel, Switzerland). Test pots (45 $\mathrm{mm}$ diameter) were prepared with discs of Chinese cabbage on tap water agar. Twenty to thirty mixed age aphids were transferred to the dishes and allowed to settle for $24 \mathrm{~h}$ at $21^{\circ} \mathrm{C}$ with a $16: 8 \mathrm{~h}$ light regime. Serial dilutions of insecticide were applied in $3 \mathrm{ml}$ of solution at 0.6 bar with 3 second settling time (equivalent to approximately $400 \mathrm{~L} / \mathrm{ha}$ ). Three replicates were used for each concentration tested and the responses were assessed after $72 \mathrm{~h}$. Aphids that were dead or seriously affected were classed as 'dead' and $\mathrm{LC}_{50}$ values were calculated by LOGIT analysis using Syngenta software.

\section{Imidacloprid Metabolism Assay}

Imidacloprid metabolism assays were carried out to determine which imidacloprid metabolites were observed in aphids and whether increased metabolism was contributing to resistance in the FRC clone. In both experiments, individual aphids of the 4106A and FRC clones were treated by topical application of imidacloprid $(0.2 \mu \mathrm{L}, 1 \mathrm{mg} / \mathrm{L}$, corresponding to the LC50 value for 4106A) using a micro-applicator as described in [7]. Owing to the physical constraints of performing topical applications to aphids, aphids were treated in batches, which resulted in a 15 minute gap between the first and last aphid being treated from each batch.

To determine which metabolites were observed in aphids, $\sim 500$ treated aphids of each clone were collected at $0,1,4$ and $24 \mathrm{~h}$ after treatment, weighed and frozen at $-20^{\circ} \mathrm{C}$. Due to the low treatment rate and volume used in this study, 500 aphids were pooled to provide one sample for each time point. To remove surface imidacloprid, aphid samples were washed in acetonitrile $(3 \times 1 \mathrm{~mL})$, after which, aphid samples were placed in extraction tubes (Precellys 24, $0.5 \mathrm{~mL}$, Lysing matrix VK05; Bertin Technologies, France) containing acetonitrile $(0.5 \mathrm{~mL})$. Samples were macerated for $5 \times 20 \mathrm{~s}$ using a FastPrep ${ }^{\circledR}$ FP120 (QBiogene, UK), centrifuged (5590g, $15 \mathrm{~min}$ ) and the resulting supernatant was transferred into HPLC vials for LC-MS/MS analysis. Separation was achieved with a Accela UPLC pump (Thermo Scientific, UK) using a Phenomoenex Luna $(\mathrm{C} 18,5 \mu \mathrm{m}, 4.60 \times 250 \mathrm{~mm})$ analytical column, with a mobile phase consisting of water $(+0.2 \%$ formic acid), and a flow rate of $0.8 \mathrm{~mL} / \mathrm{min}$. The gradient elution conditions of acetonitrile:water were as follows: $0 \min$ 10:90, $15 \mathrm{~min}$ 47.5:52.5, $15.1 \mathrm{~min}$ 80:20, $22 \mathrm{~min}$ $80: 20,22.1 \mathrm{~min} 10: 90$. The mass spectrometer used was a TSQ Vantage (Thermo Scientific) equipped with a H-ESI II source operating in positive ion mode. Analytes were detected simultaneously using selected-reaction-monitoring (SRM). SRM transitions are outlined in Additional file 1 . Scan time was $0.1 \mathrm{~s} /$ transition and the collision gas pressure was 1.5 mTorr. As noted in Additional file 1, several metabolites were available as authentic standards. For these metabolites, extraction efficiencies were determined, by spiking untreated aphid samples with a known amount $(0.05 \mu \mathrm{g})$ prior to performing the maceration and centrifugation steps, which were between $87-94 \%$. For 4/5-hydroxy-imidacloprid, only 5-hydroxy-imidacloprid was available as an authentic standard and it was thought to be unlikely that chromatographic separation of the 4and 5-hydroxy metabolites would have been achieved. Where no authentic standards were available, confirmation was made by comparison of relative retention times to previous studies [27].

In the second experiment, aphids were treated as described above, with the following modifications: 250 treated aphids of each clone were collected at 0,4 and $24 \mathrm{~h}$ after treatment, weighed and frozen at $-20^{\circ} \mathrm{C}$. Treatments were replicated three times. Aphid samples 
were washed in acetonitrile $(3 \times 0.5 \mathrm{~mL})$, placed in extraction tubes (Precellys 24, $0.5 \mathrm{~mL}$, Lysing matrix VK05) containing acetonitrile $(0.25 \mathrm{~mL})$ and prepared as described above. Recoveries of imidacloprid and 4/5hydroxy metabolite were determined using LC-MS/MS. Separation was achieved using Ultra Performance LC $^{\circledR}$ (ACQUITY UPLC-System; Waters, UK) using an ACQUITY UPLC column (HSS T3, $1.8 \mu \mathrm{m}, 100 \times 2.1$ $\mathrm{mm})$, with a mobile phase consisting of water $(+0.2 \%$ formic acid), with a flow rate of $0.6 \mathrm{~mL} / \mathrm{min}$. The gradient elution conditions of acetonitrile:water were as follows: 0 min 0:100, $0.5 \mathrm{~min}$ 0:100, $3.5 \mathrm{~min}$ 95:5, $4.5 \mathrm{~min}$ $95: 5,4.6$ min 0:100, 5.0 min 0:100. The mass spectrometer used was a Finnigan TSQ Quantum Discovery (Thermo Scientific) equipped with an Ion Max source operating in positive ion mode. Imidacloprid and 4/5hydroxy metabolite were detected simultaneously using SRM.

\section{Microarray}

The microarray (Agilent Technologies) used in this study was designed by the Georg Jander Lab and is based on a previously described array containing probes for > 10, $000 \mathrm{M}$. persicae unigenes produced by Sanger sequencing [28] augmented with an additional 30, 517 probe set designed on EST unigene sequences identified in a 454 sequencing project [29]. Microarray experiments consisted of four biological replicates and for each of these, two hybridisations were done in which the Cy3 and Cy5 labels were swapped between samples for a total of eight hybridisations between resistant and susceptible clones. Arrays were processed, scanned and the raw data normalised as described previously [7]. The TM4 suite of software from the Institute of Genomic Research was used for statistical analysis using the SAM (Significance Analysis of Microarrays) module and applying a False Discovery Rate (FDR) of zero to detect significantly differentially expressed genes [30]. Genes identified by SAM and showing a transcription ratio $>2$ fold in either direction were considered to be differentially transcribed between the two clones. Microarray data were submitted to the Gene Expression Omnibus (GEO) database (series no. GSE24629).

\section{Quantitative RT-PCR}

Quantitative RT-PCR was used to validate microarray data by examining the expression profile of selected genes. Primers were designed to amplify a fragment 90150bp in size and are listed in Additional file 4. PCR reactions were carried out as described previously [7]. Data were analysed using the geometric mean of three selected housekeeping genes (actin, para which encodes the voltage gated sodium channel, and ace, which encodes acetylcholinesterase) for normalisation according to the strategy described previously [31]. Quantitative PCR was used to determine CYP6CY3 gene copy number using genomic DNA as the template as described previously [7].

\section{Membrane preparation and $\left[{ }^{3} \mathrm{H}\right]$ imidacloprid binding}

Membranes from resistant (FRC) and susceptible (4106A) aphid clones were prepared and radioligand binding experiments performed based on previously described methods [17] with the following modifications. Aphids, ( $\sim 5 \mathrm{~g})$ were homogenized on ice in $16 \mathrm{ml}$ of pre-chilled homogenisation buffer (0.05 M Tris base, $\mathrm{pH}$ 7.4 with $\mathrm{HCl}, 200 \mu \mathrm{M}$ PMSF) with a motor-driven Ultra Turrax $(5 \times 20 \mathrm{sec}$ bursts, level 4.5$)$. The homogenate was centrifuged $\left(3,000 \mathrm{~g}, 30 \mathrm{mins}\right.$ at $\left.4^{\circ} \mathrm{C}\right)$ and resulting supernatant filtered through two layers of pre-wetted mira cloth before a final centrifugation $(83,000 \mathrm{~g}$, 60 mins at $4^{\circ} \mathrm{C}$ ). The pellet (crude membrane) was resuspended in chilled freshly prepared binding buffer (0.05 M Tris, $0.12 \mathrm{M} \mathrm{NaCl}, 100 \mu \mathrm{M}$ EDTA, pH7.4 HCl), beaded into liquid $\mathrm{N}_{2}$ and stored at $-80^{\circ} \mathrm{C}$. The protein concentration was determined by Bradford assay using BSA as a standard. Comparative saturation isotherms were performed in side-by-side fashion with appropriate time delay. $\left[{ }^{3} \mathrm{H}\right]$-imidacloprid $(1.1 \mathrm{TBq} / \mathrm{mmol}$, purity > 95\%, in-house synthesis) and methyllycaconitine (MLA, Sigma) (non-specific ligand) were prepared in binding buffer. Crude aphid membranes were defrosted on ice and diluted to $5 \mathrm{mg} / \mathrm{ml}$ in binding buffer containing $0.2 \%$ BSA. Incubations were carried out in a final volume of $1 \mathrm{ml}$ to avoid ligand depletion at very low concentrations of added $\left[{ }^{3} \mathrm{H}\right]$-imidacloprid (returned bound counts were in all cases less than $10 \%$ of added). Order of addition was binding buffer, 100 nM MLA or control, $100 \mu \mathrm{g}$ membranes followed by $\left[{ }^{3} \mathrm{H}\right]$-imidacloprid at indicated concentrations. Reactions equilibrated over 90 mins at room temperature with constant shaking and were terminated by filtration using a Brandel harvester onto Whatman GF/B filters pre-soaked in cold binding buffer with $0.25 \%$ polyethylenimine (no BSA). Filters were rapidly rinsed in a two wash cycle $(3 \mathrm{ml})$ with ice cold binding buffer (no BSA), removed, allowed to air-dry for $12 \mathrm{hrs}$ and soaked (6 hrs) in $10 \mathrm{ml}$ scintillant (Scintsafe Gel, Fisher) prior to counting.

\section{Sequence analysis of $M$. persicae nAChR subunits}

Total RNA was isolated from three pools of five adult aphids from all clones listed above and first strand cDNA synthesised as described previously [7]. PCR amplification was performed using gene-specific oligonucleotide primers designed to the published nAChR $\alpha 1$ (X81887), nAChR $\alpha 2$ (X81888), nAChR 33 (AJ236786), nAChR 44 (AJ236787), nAChR $\alpha 5$ (AJ880084) and $n A C h R \beta 1$ (AJ251838) as described previously [7]. Amplicons of the expected size 
were ethanol precipitated and sequenced directly in both directions using the BigDye mix (Applied Biosystems).

\section{Additional material}

Additional file 1: Selected-Reaction-Monitoring transitions for selected imidacloprid metabolites. Molecular weight, SRM transitions, collision energies and availability of authentic standards are detailed for 11 imidacloprid metabolites.

Additional file 2: ESTs identified by microarray analysis significantly differentially transcribed between the insecticide resistant $M$. persicae clone FRC and the susceptible clone 4106A. The full list of ESTs along with Log2, calculated fold-change values and a description based on the closest BLAST hit is detailed.

Additional file 3: Fold change in expression of $\mathrm{CYP}_{6} \mathrm{CY} 3$ and additional P450 genes in the M. persicae clones FRC and 5191A (compared to the susceptible reference clone 4106A) as determined by quantitative PCR. For each EST the most similar Acyrthosiphon pisum P450 gene is detailed.

Additional file 4: Sequences of primers used in this study. Primer sequences are listed along with the purpose for which they were used.

\section{Acknowledgements}

The authors acknowledge assistance with metabolite analysis from Simon Perry (Syngenta) and thank Frederic Magnan of Syngenta Agro S.A.S for his knowledge and help in collecting the FRC population. We thank Dr John Margaritopoulos for originally supplying the clone 5191A. Rothamsted Research is an institute of the Biotechnology and Biological Sciences Research Council (BBSRC) of the UK. This work was funded by a research grant (BB/G0352/1) from the BBSRC to CB and BB/E010601/1 to ID.

\section{Author details}

${ }^{1}$ Centre for Sustainable Pest and Disease Management, Rothamsted Research, Harpenden, AL5 2JQ, UK. ${ }^{2}$ Syngenta Crop Protection, Werk Stein, Schaffhauserstrasse, Stein, CH4332, Switzerland. ${ }^{3}$ Syngenta Crop Protection, Jealotts Hill Intl. Research Centre, Bracknell, RG42 6EY, UK.

\section{Authors' contributions}

$C B$ carried out the genomics research and analyses and drafted the manuscript. AMP carried out bioassays, nAChR sequencing and analyses and helped draft the manuscript. MA, JE and VLP carried out bioassays and associated analyses, MD and RL carried out the LC-MS/MS analyses and helped draft the manuscript, PC and AJC carried out the ligand binding analyses and helped draft the manuscript, ID, LMF, SPF, and MSW, helped direct the study and draft and critically review the manuscript, RS conceived the project and help draft and critically review the manuscript. All authors read and approved the final manuscript.

Received: 13 January 2011 Accepted: 31 May 2011

Published: 31 May 2011

\section{References}

1. Blackman RL, Eastop VF: Aphids on the world's crops, an identification and information guide. Chichester, UK: John Wiley \& Sons Ltd; 2000.

2. Devonshire AL, Field LM, Foster SP, Moores GD, Williamson MS, Blackman RL: The evolution of insecticide resistance in the peach-potato aphid, Myzus persicae. Philos Trans R Soc Lond B Biol Sci 1998, 353:1677-1684.

3. Foster SP, Cox D, Oliphant L, Mitchinson S, Denholm I: Correlated responses to neonicotinoid insecticides in clones of the peach-potato aphid, Myzus persicae (Hemiptera: Aphididae). Pest Manag Sci 2008, 64:1111-1114.

4. Margaritopoulos JT, Skouras PJ, Nikolaidou P, Manolikaki J, Maritsa K, Tsamandani K, Kanavaki OM, Bacandritsos N, Zarpas KD, Tsitsipis JA: Insecticide resistance status of Myzus persicae (Hemiptera: Aphididae) populations from peach and tobacco in mainland Greece. Pest Manag Sci 2007, 63:821-829.

5. Nauen R, Denholm I: Resistance of insect pests to neonicotinoid insecticides: Current status and future prospects. Arch Insect Biochem Physiol 2005, 58:200-215.

6. Philippou D, Field LM, Moores GD: Metabolic enzyme(s) confer imidacloprid resistance in a clone of Myzus persicae (Sulzer) (Hemiptera: Aphididae) from Greece. Pest Manag Sci 2009, 66:390-395.

7. Puinean AM, Foster SP, Oliphant L, Denholm I, Field LM, Millar NS, Williamson MS, Bass C: Amplification of a cytochrome P450 gene is associated with resistance to neonicotinoid insecticides in the aphid Myzus persicae. PLoS Genet 2010, 6:e1000999.

8. Karunker I, Benting J, Lueke B, Ponge T, Nauen R, Roditakis E, Vontas J, Gorman K, Denholm I, Morin S: Over-expression of cytochrome P450 CYP6CM1 is associated with high resistance to imidacloprid in the $B$ and $\mathrm{Q}$ biotypes of Bemisia tabaci (Hemiptera: Aleyrodidae). Insect Biochem Mol Biol 2008, 38:634-644.

9. Liu ZW, Williamson MS, Lansdell SJ, Denholm I, Han ZJ, Millar NS: A nicotinic acetylcholine receptor mutation conferring target-site resistance to imidacloprid in Nilaparvata lugens (brown planthopper). Proc Natl Acad Sci USA 2005, 102:8420-8425.

10. Puinean AM, Denholm I, Millar NS, Nauen R, Williamson MS: Characterisation of imidacloprid resistance mechanisms in the brown planthopper, Nilaparvata lugens Stål (Hemiptera: Delphacidae). Pest Biochem Physiol 2010, 97:129-132.

11. Wen Y, Liu Z, Bao H, Han Z: Imidacloprid resistance and its mechanisms in field populations of brown planthopper, Nilaparvata lugens Stål in China. Pest Biochem Physiol 2009, 94:36-42.

12. Tomizawa M, Casida JE: Neonicotinoid insecticide toxicology: Mechanisms of selective action. Annu Rev Pharmacol Toxicol 2005, 45:247-268.

13. Karlin A: Emerging structure of the nicotinic acetylcholine receptors. Neuroscience 2002, 3:102-114.

14. Huang Y, Williamson MS, Devonshire AL, Windass JD, Lansdell SJ, Millar NS: Molecular characterization and imidacloprid selectivity of nicotinic acetylcholine receptor subunits from the peach-potato aphid Myzus persicae. J Neurochem 1999, 73:380-389.

15. Casida JE: Neonicotinoid Metabolism: Compounds, Substituents, Pathways, Enzymes, Organisms, and Relevance. J Agric Food Chem 2011.

16. Nauen R, Tietjen $K$, Wagner $K$, Elbert A: Efficacy of plant metabolites of imidacloprid against Myzus persicae and Aphis gossypii (Homoptera: Aphididae). Pestic Sci 1998, 52:53-57.

17. Lind RJ, Clough MS, Reynolds SE, Earley FGP: $\left({ }^{3} H\right)$ Imidacloprid labels highand low-affinity nicotinic acetylcholine receptor-like binding sites in the aphid Myzus persicae (Hemiptera: Aphididae). Pest Biochem Physiol 1998, 62:3-14.

18. Nauen R, Jeschke P, Copping L: In Focus: Neonicotinoid insecticides. Pest Manag Sci 2008, 64:1081-1081.

19. Foster SP, Denholm I, Thompson R: Variation in response to neonicotinoid insecticides in peach-potato aphids, Myzus persicae (Hemiptera: Aphididae). Pest Manag Sci 2003, 59:166-173.

20. Li J, Shao Y, Ding Z, Bao H, Liu Z, Han Z, Millar NS: Native subunit composition of two insect nicotinic receptor subtypes with differing affinities for the insecticide imidacloprid. Insect Biochem Mol Biol 2010, 40:17-22.

21. Grutter T, Changeux JP: Nicotinic receptors in wonderland. Trends Biochem Sci 2001, 26:459-463.

22. Shimomura M, Yokota M, Ihara M, Akamatsu M, Sattelle DB, Matsuda K: Role in the selectivity of neonicotinoids of insect-specific basic residues in loop D of the nicotinic acetylcholine receptor agonist binding site. $\mathrm{Mol}$ Pharmacol 2006, 70:1255-1263.

23. Tomizawa M, Casida JE: Selective toxicity of neonicotinoids attributable to specificity of insect and mammalian nicotinic receptors. Annu Rev Entomol 2003, 48:339-364.

24. Talley TT, Harel M, Hibbs RE, Radic Z, Tomizawa M, Casida JE, Taylor P: Atomic interactions of neonicotinoid agonists with AChBP: Molecular recognition of the distinctive electronegative pharmacophore. Proc Natl Acad Sci USA 2008, 105:7606-7611.

25. Markussen DKM, Kristensen M: Low expression of nicotinic acetylcholine receptor subunit Mda2 in neonicotinoid-resistant strains of Musca domestica L. Pest Management Science 2010, 66:1257-1262. 
26. Potter C: An improved laboratory apparatus for applying direct sprays and films, with data on the electrostatic charge on atomized spray fluids. Ann Appl Biol 1952, 39:1-29.

27. Ford KA, Casida JE: Chloropyridinyl neonicotinoid insecticides: Diverse molecular substituents contribute to facile metabolism in mice. Chem Res Toxicol 2006, 19:944-951.

28. Ramsey JS, Wilson ACC, de Vos M, Sun Q, Tamborindeguy C, Winfield A, Malloch G, Smith DM, Fenton B, Gray SM, Jander G: Genomic resources for Myzus persicae: EST sequencing, SNP identification, and microarray design. BMC Genomics 2007, 8:423.

29. Ramsey JS, Rider DS, Walsh TK, De Vos M, Gordon KHJ, Ponnala L, Macmil SL, Roe BA, Jander G: Comparative analysis of detoxification enzymes in Acyrthosiphon pisum and Myzus persicae. Insect Mol Biol 2010, 19:155-164.

30. Saeed Al, Sharov V, White J, Li J, Liang W, Bhagabati N, Braisted J, Klapa M, Currier T, Thiagarajan M, Sturn A, Snuffin M, Rezantsev A, Popov D, Ryltsov A, Kostukovich E, Borisovsky I, Liu Z, Vinsavich A, Trush V, Quackenbush J: TM4: A free, open-source system for microarray data management and analysis. Biotechniques 2003, 34:374-378.

31. Vandesompele J, Preter KD, Pattyn F, Poppe B, Roy NV, Paepe AD, Speleman F: Accurate normalization of real-time quantitative RT-PCR data by geometric averaging of multiple internal control genes. Genome Biol 2002, 3 .

doi:10.1186/1471-2202-12-51

Cite this article as: Bass et al:: Mutation of a nicotinic acetylcholine receptor $\beta$ subunit is associated with resistance to neonicotinoid insecticides in the aphid Myzus persicae. BMC Neuroscience 2011 12:51.

\section{Submit your next manuscript to BioMed Central} and take full advantage of:

- Convenient online submission

- Thorough peer review

- No space constraints or color figure charges

- Immediate publication on acceptance

- Inclusion in PubMed, CAS, Scopus and Google Scholar

- Research which is freely available for redistribution

Submit your manuscript at www.biomedcentral.com/submit
Biomed Central 